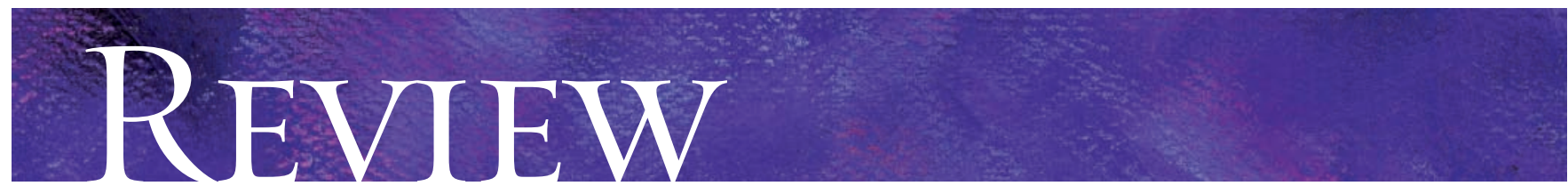

\title{
Heterozygous familial hypercholesterolemia: an underrecognized cause of early cardiovascular disease
}

\author{
George Yuan, Jian Wang, Robert A. Hegele
}

\section{ABSTRACT}

Heterozygous familial hypercholesterolemia ( $\mathrm{HeFH})$ is a monogenic disorder that affects about 1 in 500 people, with a higher prevalence in certain subpopulations such as people of Quebecois, Christian Lebanese and Dutch South Afrikaner extraction. HeFH is characterized by cholesterol deposits affecting the corneas, eyelids and extensor tendons; elevated plasma concentrations of low-density lipoprotein (LDL) cholesterol; and accelerated vascular disease, especially coronary artery disease (CAD). Although $\mathrm{HeFH}$ is genetically heterogeneous, it is most often caused by heterozygous mutations in the $L D L R$ gene encoding the $L D L$ receptor. We describe a man who was diagnosed with $\mathrm{HeFH}$ after he had a myocardial infarction at 33 years of age. By DNA sequence analysis, he was found to have a heterozygous splicing mutation in his $L D L R$ gene. This discovery expanded the growing mutational spectrum in patients with $\mathrm{HeFH}$ in Ontario.

Given that $\mathrm{HeFH}$ is a treatable cause of early vascular disease, it is important that this condition be recognized, diagnosed and treated in affected patients; but as yet, there is no consensus on the best approach. Diagnostic criteria based on family history and clinical presentation have been proposed for patients with suspected HeFH. Biochemical or molecular screening might be considered to detect new cases of HeFH in populations with a relatively high $\mathrm{HeFH}$ prevalence and a relatively small number of possible causative mutations. So far, however, the most cost-effective and efficient systematic strategy to detect previously undiagnosed cases of $\mathrm{HeFH}$ is still cascade testing: clinical and biochemical screening of close relatives of the proband patient diagnosed with $\mathrm{HeFH}$. Pharmacologic treatment of HeFH is cost-effective.

CMAJ 2006;174(8):II24-9

$\mathrm{H}$ eterozygous familial hypercholesterolemia $(\mathrm{HeFH})$ is an autosomal dominant disease characterized by markedly elevated plasma concentrations of lowdensity lipoprotein (LDL) cholesterol (LDL-C), typically well above the 95th percentile for age and sex. ${ }^{1}$ Because HeFH is not only relatively common and associated with a high risk of early coronary artery disease (CAD) but is easily treatable with LDL-C-lowering strategies, this genetic disorder meets the World Health Organization (WHO) criteria for systematic screening. ${ }^{2} \mathrm{WHO}$ has estimated that $\mathrm{HeFH}$ is properly diag- nosed in only about $15 \%$ of affected Canadians. ${ }^{2}$ As many as $30 \%$ of patients do not survive their first myocardial infarction (MI); early detection of $\mathrm{HeFH}$ therefore has the potential to save many lives and prevent early morbidities related to CAD. ${ }^{3,4}$ To illustrate, we describe a patient whose $\mathrm{HeFH}$ was diagnosed subsequent to his early MI.

\section{An illustrative case}

A 34-year-old man of Irish ancestry was referred to the Lipid Genetics Clinic of the London Health Sciences Centre for dyslipidemia management. He had been in good general health until the age of 29 years, when routine blood tests returned a plasma total cholesterol (TC) result of $\mathrm{Io} \mathrm{mmol} / \mathrm{L}$ and an LDL-C concentration of $8 \mathrm{mmol} / \mathrm{L}$. The patient could not recall receiving specific medical advice at that time. His family history included premature CAD: his father and 2 paternal uncles each had elevated plasma levels of LDL-C and died of MI before 50 years of age.

At age 33, the patient experienced an acute MI. Angiography showed widespread CAD that required the placement of 3 stents. Daily oral drug therapy was initiated for secondary CAD prevention: atorvastatin ( $80 \mathrm{mg}$ ), ezetimibe (Io $\mathrm{mg}$ ), ramipril $(5 \mathrm{mg})$, clopidogrel $(75 \mathrm{mg})$, bisoprolol $(5 \mathrm{mg})$ and ASA (8I mg). At 6 months after his MI, his serum TC and LDL$\mathrm{C}$ concentrations were 5.36 and $3.76 \mathrm{mmol} / \mathrm{L}$, respectively; at 9 months after, 4.23 and $2.90 \mathrm{mmol} / \mathrm{L}$. Rosuvastatin (40 mg) was substituted for atorvastatin at 9 months. At 12 months post-MI (i.e., 3 months later), his TC and LDL-C concentrations were 4.05 and $2.50 \mathrm{mmol} / \mathrm{L}$, respectively; at 15 months, 4.28 and $2.46 \mathrm{mmol} / \mathrm{L}$.

On examination, his weight was IIo kg, height $192 \mathrm{~cm}$, body mass index $30 \mathrm{~kg} / \mathrm{m}^{2}$ and blood pressure $\mathrm{I} 20 / 80 \mathrm{~mm} \mathrm{Hg}$. He had bilateral corneal arcus and bilateral xanthomas of his Achilles tendons and the extensor tendons of his hands (Fig. I). These physical findings, together with his medical history of high plasma LDL-C concentrations and family history of premature $\mathrm{CAD}$, led to a clinical diagnosis of HeFH. Sequence analysis of genomic DNA from leukocytes taken from the patient's peripheral blood revealed a splicing mutation at the splice donor site in intron I4 of the LDLR gene encoding the LDL receptor. This same mutation was previously reported in Utah among people of European descent with $\mathrm{HeFH} .{ }^{5}$ The mutation alters the splicing of $\mathrm{mRNA}^{5}$ and produces a severely truncated LDL-receptor protein. The patient was a sim- 
ple heterozygote; that no other mutations were found provided molecular confirmation of the clinical diagnosis of $\mathrm{HeFH}$. The mutation expanded the spectrum of LDLR mutations that have been found among Ontarians with $\mathrm{HeFH}$ (see the online Appendix 1, available at www.cmaj.ca/cgi/content /full/174/8/1124/DC1).

\section{Epidemiology}

$\mathrm{HeFH}$ affects about 1 in 500 people, with higher rates because of genetic founder effects (i.e., the introduction of mutations by a few "pioneers" or population founders) among people of Quebecois, Christian Lebanese and Dutch South Afrikaner extraction. ${ }^{6}$ If undiagnosed and untreated, the cumulative risk of CAD by age 60 years is more than $60 \%$ among men and more than $30 \%$ among women with $\mathrm{HeFH} .^{7-9}$ Among people with $\mathrm{HeFH}$ in Quebec, CAD onset is generally at around 40 years of age in men and about 50 years in women. ${ }^{10}$ According to $\mathrm{WHO}$, only some $15 \%$ of Canadian residents with $\mathrm{HeFH}$ have had it diagnosed. ${ }^{2}$ About $10 \%$ of cardiologists and general practitioners screen their patients for $\mathrm{HeFH} .{ }^{2,11}$ Because death immediately after $\mathrm{MI}$ is so frequent and because the medical management of $\mathrm{HeFH}$ is easy, the desirability of safe, effective and early diagnosis and institution of preventive treatments seem obvious. Less obvious is the most costeffective approach to identify Canada's estimated 6o ooo-80 ooo people with $\mathrm{HeFH}$.

\section{Genetics}

Familial clustering of tendon xanthomas, high serum cholesterol and early MIs was first noted by Müller in 1939. ${ }^{12}$ Later, in a series of brilliant experiments that culminated in the 1985 Nobel Prize in Medicine and Physiology, Brown and Goldstein ${ }^{1}$ discovered the LDL receptor, a cell-surface glycoprotein that binds the apolipoprotein (apo) B moiety on the LDL particle as part of the process of receptor-mediated endocytosis. HeFH patients were found to have one copy of a mutated $L D L R$ gene, which normally is located on chromosome igpi3 and comprises 18 exons. ${ }^{1}$ The catabolic defect in $\mathrm{HeFH}$ patients results in a doubling of plasma LDL-C concentration. Extremely rare patients - about 1 in a million people - have homozygous familial hypercholesterolemia (HoFH) because of mutations in both copies of their LDLR gene, with plasma LDL-C concentrations increased up to Io-fold and eye, skin, tendon and vascular atherosclerotic disease in childhood. ${ }^{1}$

Genetic studies over the past 20 years have shown that various $L D L R$ mutations
- of a total of about 800 - are found in most HeFH patients. ${ }^{13-16}$ Less commonly, the HeFH phenotype can result from a heterozygous mutation within the receptor-binding domain of $A P O B$ encoding apo B-Ioo. ${ }^{14}$ Recently, 2 other genes called ARH and PCSKg were shown to cause a HoFHand a HeFH-like phenotype, respectively, ${ }^{14}$ but these non$L D L R$ causes of familial hypercholesterolemia are very rare.

\section{Clinical features}

In patients with $\mathrm{HeFH}$, the liver's capacity to catabolize LDL-C in a regulated manner is impaired. LDL-C residence time in plasma is therefore prolonged, and the propensity of the cholesterol particles to undergo oxidation increased. The modified LDL particles are taken up by macrophages by means of an unregulated scavenger receptor, which causes cholesterol-laden foam cells to form. These can lead to clinical manifestations (Fig. I). Cholesterol deposits within the

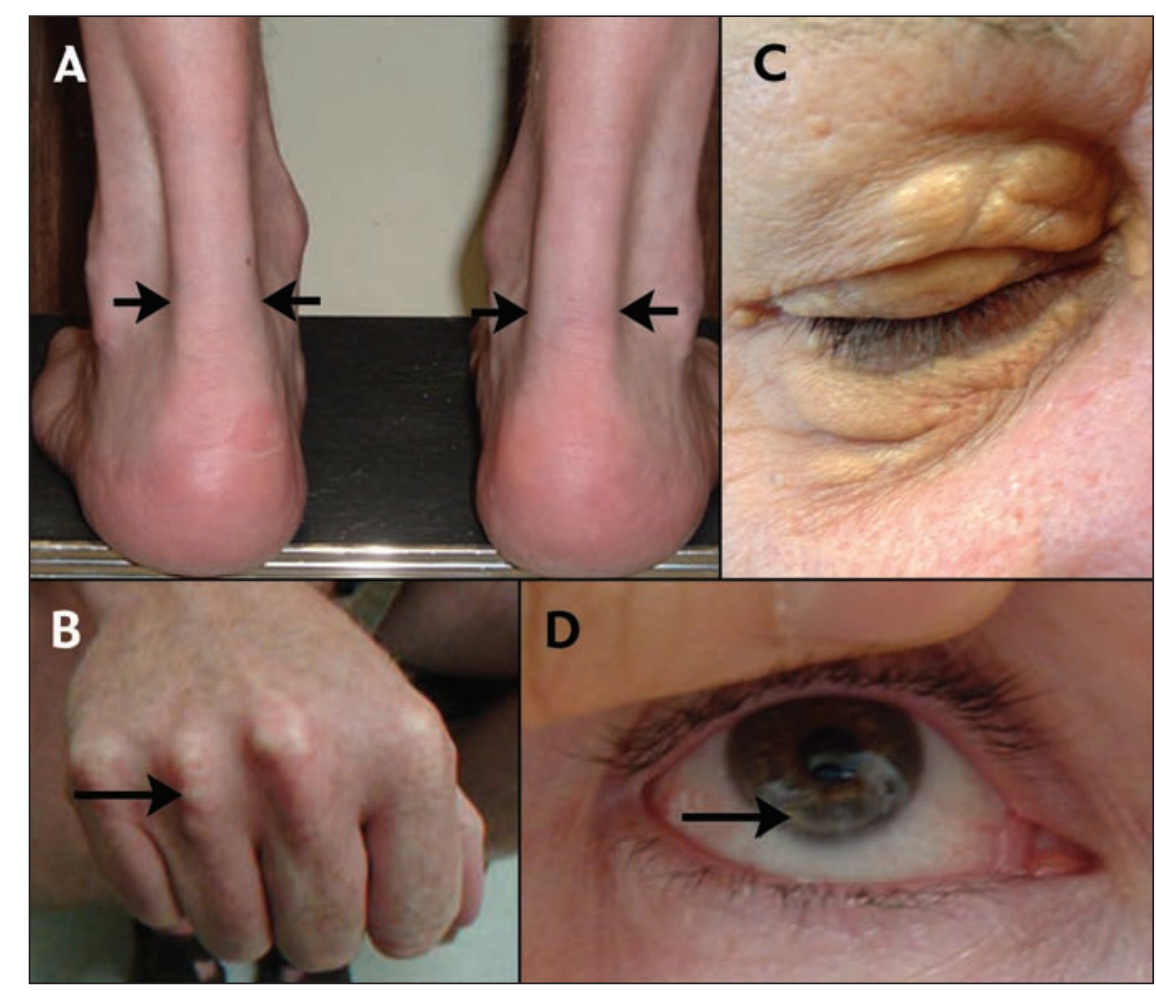

Fig. 1: Physical signs of heterozygous familial hypercholesterolemia (HeFH), which result from cholesterol deposited within macrophages in specific sites. Tendinous xanthomas, for example, manifest first as thickening of, and later as deposits within, extensor tendons. A: Lateral borders of thickened Achilles' tendons are shown with arrows. B: Tendinous xanthomas can also occur in the extensor tendons of the hands (shown), feet, elbows and knees. C: Xanthelasmas are cholesterol deposits in the eyelids. D: Arcus cornealis results from cholesterol infiltration around the corneal rim (arrow). Deposits in and around the eye tend to be more specific for $\mathrm{HeFH}$ in people younger than 45 years; in elderly people, they are less likely to be associated with blood lipoprotein abnormalities, for instance in the case of arcus senilis.

Some patients may report having observed cutaneous cholesterol deposition in response to a functional enquiry. People with HeFH have been known to undergo cosmetic eyelid surgery to remove xanthelasmas - even repeatedly, for lesions that continued to recur - without ever having had their plasma lipoprotein profiles determined. 
Box 1: Dutch Lipid Network clinical criteria for diagnosis of heterozygous familial hypercholesterolemia (HeFH)

\section{Criteria}

Points

1. Family history: a first-degree relative (a parent, offspring or sibling of the patient) with known

a) Premature* coronary and vascular disease

b) Plasma LDL-C concentration > 95th percentile for age and sex

I) In an adult relative

II) In a relative $<18$ years of age

c) Tendon xanthomata or arcus cornealis

2. Clinical history: patient has premature*

a) Coronary artery disease

b) Cerebral or peripheral vascular disease

3. Physical examination of the patient

a) Tendon xanthomata

b) Arcus cornealis in a patient $<45$ years of age

4. LDL-C levels in patient's blood, mmol/L
a) $\geq 8.5$
b) $6.5-8.4$
c) $5.0-6.4$
d) $4.0-4.9$

8

5. DNA analysis showing a functional mutation in the LDLR or other HeFH-related gene

$\begin{array}{cc}\text { Diagnosis } & \text { Total points } \\ \text { Definite HeFH } & >8 \\ \text { Probable HeFH } & 6-8 \\ \text { Possible HeFH } & 3-5\end{array}$

Note: LDL-C = low-density lipoprotein cholesterol.

*If a male relative, $<55$ years of age; if a female relative, $<60$ years.

skin of the eyelids, for instance, are called xanthelasmas; those in connective tissues within and surrounding extensor tendons, especially the Achilles and extensor tendons of the hands, are called xanthomas; and deposits along the corneal margin are called arcus cornealis or corneal arcus. The most dangerous deposits occur within arteries, where they have potential to cause premature CAD, stroke and peripheral vascular disease. ${ }^{1}$

The medical history of the proband patient highlights the marked risk of early CAD associated with $\mathrm{HeFH}$. For instance, findings from a prospective evaluation in I980-I989 (i.e., in the pre-statin era) of 526 patients with $\mathrm{HeFH}$ (2234 personyears) through the Simon Broome Register essentially reflected the natural history of $\mathrm{HeFH} .{ }^{17}$ Excess rates of death from $\mathrm{CAD}$ in people with $\mathrm{HeFH}$ were highest between the ages of 20 and 39 years (standardized mortality ratio [SMR] 9686, $95 \%$ confidence interval [CI] 3670-2I 800). SMR for all causes was $\mathrm{I}_{3} 3$ (95\% CI II7-273) and was highest between the ages of 20 and 39 years (SMR 902, 95\% CI 329-I950). Thus, HeFH was associated with a markedly increased risk of death, especially among young adults.
Box 2: Simon Broome Register criteria for diagnosis of heterozygous familial hypercholesterolemia (HeFH)

\section{Criteria}

A A plasma cholesterol measurement of either:

- Total cholesterol $>7.5 \mathrm{mmol} / \mathrm{L}$ (adult patient) or $>6.7 \mathrm{mmol} / \mathrm{L}$ (child aged $<16 \mathrm{yr}$ )

- Low-density lipoprotein $>4.9 \mathrm{mmol} / \mathrm{L}$ (adult patient) or $>4.0 \mathrm{mmol} / \mathrm{L}$ (child aged < $16 \mathrm{yr}$ )

B Tendon xanthomas in the patient or any of the patient's first- or second-degree relatives*

C DNA-based evidence in the patient of mutation in $L D L R$ or any other HeFH-related gene

D Family history of myocardial infarction before the age of

- $50 \mathrm{yr}$, in any first- or second-degree relative*

- $60 \mathrm{yr}$, in any first-degree relative*

E Family history of plasma total cholesterol measurements $>7.5 \mathrm{mmol} / \mathrm{L}$ in any first- or second-degree relative*

\begin{tabular}{cll} 
Diagnosis & \multicolumn{2}{l}{ Criteria required } \\
Definite HeFH & $\mathrm{A}+\mathrm{B}$ or $\mathrm{C}$ \\
Probable HeFH & $\mathrm{A}+\mathrm{D}$ or $\mathrm{A}+\mathrm{E}$
\end{tabular}

*First-degree relation = parent, offspring or sibling; second-degree relation = grandparent, grandchild, nephew, niece or half-sibling.

\section{Diagnosis}

In the context of primary $\mathrm{CAD}$ prevention, $\mathrm{HeFH}$ should be suspected by an incidental discovery of elevated plasma concentrations of TC or LDL-C; a family history of premature onset of symptomatic CAD (i.e., in a first-degree male relative under the age of 55 or a first-degree female relative under the age of 60 years) or even very high test results for TC or LDL-C; and suggestive physical findings (Fig. I). For secondary CAD prevention, patients in whom atherosclerotic disease developed at a young age should be carefully evaluated for $\mathrm{HeFH}$.

The clinical diagnosis of $\mathrm{HeFH}$ typically requires a combination of evidence from family history, clinical history, physical signs and biochemical markers (Box I, Box 2). Diagnostic guidelines for $\mathrm{HeFH}$ diagnosis in patients who either are ${ }^{18}$ or are not ${ }^{19}$ part of a family with known $\mathrm{HeFH}$ members are shown in Box I, Box 2 and Table I. Because of Mendel's laws, a plasma LDL-C level above a critical threshold becomes a highly specific diagnostic marker when one family member has been diagnosed with $\mathrm{HeFH}$ (Table I). The diagnostic value of newer biochemical analytes, such as apo B, is promising but not yet established.

$\mathrm{HeFH}$ is most effectively diagnosed when a family member is already known to have HeFH. With use of molecular diagnosis as the "gold standard," the Utah Medical Pedigrees project to Make Early Diagnoses and Prevent Early Deaths (MEDPED) for people with familial hypercholesterolemia showed that a screening test that uses plasma LDL-C limits to attain $98 \%$ specificity would detect $\mathrm{HeFH}$ in the general population with only $54 \%$ sensitivity ${ }^{18}$ In contrast, the greater likelihood of a positive diagnosis with use of the same 
Table 1: Low-density lipoprotein (LDL) cholesterol thresholds to diagnose heterozygous familial hypercholesterolemia (HeFH) with $98 \%$ specificity in a patient, by degree of relatedness to his or her closest relative with known HeFH

\begin{tabular}{lcccc}
\hline & \multicolumn{3}{c}{ LDL cholesterol concentration, mmol/L } \\
\cline { 2 - 4 } $\begin{array}{l}\text { Patient's } \\
\text { age, yr }\end{array}$ & \begin{tabular}{l} 
Degree of relatedness to patient \\
\cline { 2 - 4 }
\end{tabular} & $\begin{array}{c}\text { Average } \\
\text { in general } \\
\text { population }\end{array}$ \\
\hline$<18$ & 4.0 & 4.3 & 4.4 & 5.2 \\
\hline $18-29$ & 4.4 & 4.6 & 4.8 & 5.7 \\
\hline $30-39$ & 4.9 & 5.2 & 5.4 & 6.2 \\
\hline 40 & 5.3 & 5.6 & 5.8 & 6.7 \\
\hline
\end{tabular}

*Parent, offspring or sibling.

†Grandparent, grandchild, nephew, niece or half-sibling.

‡Great-grandparent, first cousin, great-grandchild.

screening method (but with relatively low plasma LDL-C thresholds, compared with the diagnostic levels used for screening of the general population) in relatives of patients already known to have $\mathrm{HeFH}$ was highly effective: ${ }^{18}$ while specificity remained high at $98 \%$, sensitivity improved to $88 \%$ for first-degree relatives, $85 \%$ for second- and $81 \%$ for thirddegree relatives because of the greater likelihood of a positive diagnosis. The authors ${ }^{18}$ strongly recommended biochemical screening of relatives of patients found to have HeFH (an approach that has been called cascade testing) ${ }^{20}$ over other detection strategies such as population-wide LDL-C testing.

Most often, a diagnosis of $\mathrm{HeFH}$ in a family member has not already been made, so standard diagnostic criteria are required. The Dutch Lipid Network (DLN) ${ }^{2,19}$ (Box I) and the United Kingdom Simon Broome Register (SBR) ${ }^{17}$ (Box 2) have suggested diagnostic criteria for $\mathrm{HeFH}$ that use various clinical, biochemical and molecular genetic attributes. More than $80 \%$ of people with a DLN score above 8 had genetic mutations; this threshold was therefore used to specify individuals with "definite" HeFH. ${ }^{19}$ The SBR guidelines required documentation of tendon xanthomas, which are very specific for HeFH but relatively insensitive, since they are not clinically apparent in about $30 \%$ of people with $\mathrm{HeFH}$ and often not until the fourth decade of life..$^{17,21}$

Efficacy of the DLN and SBR criteria was evaluated recently in a study involving 408 Danes with HeFH. ${ }^{21}$ Molecular diagnosis revealed little difference in sensitivity and specificity between the DLN and SBR criteria (Table 2), which suggests that either approach would be helpful in clinical diagnosis (although each left much to be desired).

Routine molecular genetic testing to diagnose $\mathrm{HeFH}$ is unclear at this time. Civeira and associates ${ }^{22}$ recommended limiting genetic analysis to populations in which only a few LDLR mutations account for most $\mathrm{HeFH}$ cases; populations in which most causative mutations are known and rapid inexpensive genetic tools have been developed; and subjects with an uncertain clinical diagnosis who are members of HeFHaffected families in which the mutation is already known. Leren and colleagues ${ }^{23}$ further suggested that with cascade testing a clinical and biochemical diagnosis might be insuffi- cient, and that DNA testing would increase diagnostic certainty. However, this position remains controversial for many care providers, including ourselves. The potential value of genetic diagnosis of $\mathrm{HeFH}$ in Canada is context-dependent.

In Quebec, about $90 \%$ of patients with $\mathrm{HeFH}$ will have 1 of about 11 mutations (Appendix 1, www.cmaj.ca/cgi/content/full /174/8/1124/DC1), and in some areas over $80 \%$ of patients will have 1 of 5 or fewer possible mutations. ${ }^{6,24-30}$ Furthermore, the incidence of $\mathrm{HeFH}$ in Quebec is about 2.5-fold higher than in the rest of Canada because of founder effects. ${ }^{6,27}$ Quebec's high incidence and prevalence of $\mathrm{HeFH}$ and high rate of recurrence of mutation in affected people make diagnostic DNA testing a reasonable consideration. In contrast, there are very few recurrent $\mathrm{HeFH}$ mutations among Ontario patients (Appendix 1, www.cmaj.ca/cgi/content/full/174/8/1124/DC1). Screening of a person's entire $L D L R$ gene to detect one of many possible known or unknown mutations is more costly than a dedicated screening method designed to provide a simple positiveor-negative result for a few well-characterized $L D L R$ mutations. Population-based genetic findings indicate that, with current technologies, DNA-based diagnosis of $\mathrm{HeFH}$ cannot yet be routinely considered in Ontario patients.

Thus, in nonfounder populations, there appear to be general obstacles to the imminent use of routine diagnostic genetic testing. Perhaps fortuitously, these impediments permit us to defer the potential psychological and ethical issues that might arise from DNA analysis. Pilot studies seem to indicate that the attitudes of members of HeFH families toward genetic methods of diagnosis are generally favourable. ${ }^{31}$ However, even without DNA testing, potential issues arise from approaching relatives to detect $\mathrm{HeFH}$ by screening plasma LDL-C. For instance, clinical geneticists in Canada have traditionally relied on probands to contact at-risk relatives (i.e., family contact) and advise them of the need for screening. But since $\mathrm{HeFH}$ is potentially fatal and easily treatable, some European investigators have argued that it is acceptable, and

Table 2: Performance of various diagnostic criteria in the prediction of HeFH-related DNA mutations in patients

\begin{tabular}{|c|c|c|}
\hline Test & Sensitivity, \% & Specificity, \% \\
\hline \multicolumn{3}{|l|}{ Biochemical only } \\
\hline \multicolumn{3}{|c|}{ Utah MEDPED (families) } \\
\hline Total cholesterol & 63.4 & 73.4 \\
\hline LDL cholesterol & 70.3 & 69.8 \\
\hline \multicolumn{3}{|l|}{ Clinical } \\
\hline \multicolumn{3}{|l|}{ Dutch Lipid Network } \\
\hline Definite & 41.5 & 87.9 \\
\hline Probable & 66.7 & 64.5 \\
\hline Possible & 99.3 & 5.9 \\
\hline \multicolumn{3}{|c|}{ Simon Broome Register } \\
\hline Definite & 34.1 & 89.4 \\
\hline Possible & 90.4 & 28.6 \\
\hline
\end{tabular}

Note: $\mathrm{HeFH}=$ heterozygous familial hypercholesterolemia, $\mathrm{MEDPED}=$ Make Early Diagnosis to Prevent Early Deaths (Medical Pedigree project), LDL = low-density lipoprotein. 
more efficient, for a health care worker to contact relatives on behalf of the consenting proband (direct contact). HeFH family-contact programs in Norway ${ }^{31}$ and direct-contact programs in Holland ${ }^{32}$ show no apparent differences in the reactions of contacted relatives. In general, relatives believed strongly that the contact had been beneficial.

\section{Treatment}

Once a diagnosis of $\mathrm{HeFH}$ has been made, treatment is relatively straightforward. Experience has shown that even when very elevated plasma TC concentrations are detected in a young adult (as in this report's proband), specific treatments or follow-up are not always advised. However, current treatment guidelines such as those from the Canadian Hypercholesterolemia Working Group ${ }^{33}$ recommend target LDL-C levels under $2.5 \mathrm{mmol} / \mathrm{L}$ for primary CAD prevention in patients at high risk, such as those with $\mathrm{HeFH}$.

$\mathrm{CAD}$ prevention in $\mathrm{HeFH}$ requires a global risk-reduction program that focuses on modifiable risk factors, including weight control, prudent diet, moderate exercise, smoking cessation and appropriate control of diabetes and hypertension. ${ }^{33}$ The dietary protocol in HeFH minimizes cholesterol intake and replaces saturated fats with unsaturated fats. ${ }^{34}$ Consumption of plant sterols and stanols can also reduce plasma LDL-C levels by about Io\%. ${ }^{35,36}$

Pharmacotherapy is frequently required in $\mathrm{HeFH}$ patients because the plasma LDL-C targets usually cannot be reached with diet and lifestyle changes alone. ${ }^{37}$ Statins - also known as 3-hydroxy-3-methylglutaryl-coenzyme A (HMG-CoA) reductase inhibitors - have become the agents of first choice. They block the rate-limiting step of cholesterol synthesis in the liver, depleting liver cholesterol content and upregulating the expression of cell-surface LDL receptor, which results in increased removal of LDL from plasma. ${ }^{1}$ Subjects with $\mathrm{HeFH}$ have 1 normal LDLR allele to upregulate. Plasma LDL-C reductions of up to $50 \%$ can be achieved with higher-dose statin monotherapy, ${ }^{38-44}$ although higher doses may be associated with an increased risk of adverse events.

Because of their high baseline levels of plasma LDL-C, patients with $\mathrm{HeFH}$ generally require more than 1 medication to reach targets. Ezetimibe, a cholesterol absorption inhibitor that appears well tolerated, is now increasingly used in combination with statins in people who require large absolute and relative reductions in plasma LDL-C levels, such as those with $\mathrm{HeFH}$. When used in combination with a statin, a further decrease in plasma LDL-C concentration of up to $25 \%$ has been seen with ezetimibe. ${ }^{45}$ Other agents such as bileacid sequestrants and niacin preparations have also been used as part of combination therapy regimens to reduce plasma LDL-C in patients with $\mathrm{HeFH}_{0}{ }^{46,47}$

A common clinical concern is the approach to primary CAD prevention when HeFH has been diagnosed in children or adolescents. Dietary and lifestyle advice form the therapeutic foundation. Drug treatment of pediatric $\mathrm{HeFH}$ is an evolving field. Bile-acid sequestrants have the advantage of not being systemically absorbed, but they are poorly tolerated. Tolerability is also an issue with short-acting niacin preparations. Ezetimibe has theoretical advantages, but at present is not indicated for use in children or adolescents. Statin trials involving children and adolescents so far have been short-term: 6 months for atorvastatin, ${ }^{41} 1$ year for lovastatin ${ }^{38}$ and simvastatin, ${ }^{39}$ respectively, and 2 years for pravastatin. ${ }^{42}$ Over relatively short periods, no difference in clinically significant adverse events was apparent between the placebo and statin-treated groups. Mean decreases in LDL-C ranged from about $25 \%$ to $45 \% .^{38-40,42}$ The 2-year pravastatin study showed significant regression of intima-media thickening in the carotid arteries..$^{42}$ In 2005, Health Canada approved atorvastatin for treatment of $\mathrm{HeFH}$ in boys and postmenarche girls aged Io-17 years if their LDLC levels were $4.9 \mathrm{mmol} / \mathrm{L}$ or greater; their levels were at least 4.I $\mathrm{mmol} / \mathrm{L}$ with a family history for premature $\mathrm{CAD}$; or they had 2 or more risk factors for CAD. However, the exact time to initiate treatment and the applicability of adult targets in children are uncertain. Referral for a specialist's opinion remains a very appropriate alternative for children with $\mathrm{HeFH}$.

Drug treatment of $\mathrm{HeFH}$ is very cost-effective. For example, in primary CAD prevention, treatment with lovastatin for Io years was shown to save both lives and money (i.e., negative cost per life-year saved) among men aged 35-44 years with $\mathrm{HeFH}$ but no other risk factors, and among women aged 35-44 with $\mathrm{HeFH}$ and at least 1 additional risk factor. ${ }^{43}$ In the Netherlands, cascade testing to detect new HeFH patients who then received statin treatment prevented 26 MIs for every Ioo people aged 20-60 treated for Io years, gaining a mean of 3.3 years of life for each patient so found and treated. ${ }^{44}$ The total lifetime cost for screening and testing, lifetime drug treatment and treatment of CAD events was about Can $\$ 9000$ per new case detected, and the cost per life-year gained was about \$I 000..$^{44}$ In England, the cost per death avoided over Io years of use of cascade testing to detect $\mathrm{HeFH}$ and treat such patients with statins was around $\$ 7000 .^{48}$

\section{Conclusion}

Had the proband we have described received a clinical diagnosis of $\mathrm{HeFH}$ before his MI, initiation of treatment to lower his elevated plasma LDL-C levels would likely have delayed the onset of vascular symptoms. Diagnosis of HeFH is based on clinical and biochemical criteria, with no single set of criteria clearly superior to the others. Nevertheless, the proband reported herein would have met clinical criteria for definite HeFH by either DLN ${ }^{19}$ or SBR criteria, ${ }^{17}$ even without DNA testing. Cascade testing of relatives of people known to have $\mathrm{HeFH}$ appears to be an effective strategy to detect new cases (the proband patient's relatives are in the process of being clinically screened). The population genetics of $\mathrm{HeFH}$ precludes advice favouring the routine use of DNA testing to diagnose $\mathrm{HeFH}$ at this time. Cost-benefit analyses have suggested that family-based ascertainment and drug treatment of $\mathrm{HeFH}$ represents good value for money. Most patients who are affected require combination drug treatment to lower their plasma LDL-C concentrations. Finally, although our experience with pharmacotherapy in children and adolescents with $\mathrm{HeFH}$ has been increasing, the risks and benefits of their use must be carefully evaluated for individual patients. 
This article has been peer reviewed.

From the Department of Medicine (Yuan, Hegele), Schulich School of Medicine and Dentistry, University of Western Ontario, and the Blackburn Cardiovascular Genetics Laboratory (Wang, Hegele), Robarts Research Institute, London, Ont.

Competing interests: None declared for George Yuan and Jian Wang. Robert Hegele has received speaker's fees from, and is an ongoing paid consultant of, AstraZeneca, Fournier, Merck Frosst, Merck Shering, Pfizer and Oryx.

Contributors: All authors contributed substantially to the case description, the acquisition and interpretation of the information reviewed, and the iterative rewriting process. All approved the final version of the manuscript.

Acknowledgements: We greatly appreciate the expert technical assistance of Ms. Brooke Miskie, Ms. Stefanie Bombardier and Mr. Matthew Ban.

This research was supported by the Jacob J. Wolfe Chair in Functional Genomics, the Edith Schulich Vinet Canada Research Chair (Tier I) in Human Genetics, a Career Investigator award from the Heart and Stroke Foundation of Ontario and operating grants from the Canadian Institutes for Health Research, the Heart and Stroke Foundation of Ontario, the Ontario Research and Development Challenge Fund (99-0507) and Genome Canada. George Yuan was supported by the University of Western Ontario Summer Research Training Program and by the Heart and Stroke Foundation of Ontario Irwin Bernick Scholarship.

\section{REFERENCES}

I. Brown MS, Goldstein JL. A receptor-mediated pathway for cholesterol homeostasis. Science I986;232:34-47.

2. Word Health Organization-Human Genetics (editors). DoNDP, familial hypercholesterolaemia: report of a second WHO Consultation. Geneva: WHO; I999.

3. Kuch B, Bolte HD, Hoermann A, et al. What is the real hospital mortality from acute myocardial infarction? Eur Heart J 2002;23:714-20.

4. Rosamond WD, Chamblesss LE, Folsom AR, et al. Trends in the incidence of myocardial infarction and in mortality due to coronary heart disease, 1987 to 1994. N Engl J Med I998;339:86I-7.

5. Takada D, Emi M, Ezura Y, et al. Interaction between the LDL-receptor gene bearing a novel mutation and a variant in the apolipoprotein A-II promoter: molecular study in a II35-member familial hypercholesterolemia kindred. JHum Genet 2002;47:656-64

6. Hobbs HH, Brown MS, Russell DW, et al. Deletion in the gene for the low-densitylipoprotein receptor in a majority of French Canadians with familial hypercholesterolemia. NEngl J Med ig87;317:734-7.

7. Slack J. Risks of ischaemic heart-disease in familial hyperlipoproteinaemic states. Lancet I969;2(7635):1380-2.

8. Stone NJ, Levy RI, Fredrickson DS, et al. Coronary artery disease in II6 kindreds with familial type II hyperlipoproteinemia. Circulation 1974;49:476-88.

9. Austin MA, Hutter CM, Zimmern RL, et al. Familial hypercholesterolemia and coronary heart disease: a HuGE association review. Am J Epidemiol 2004;160:42I-9.

Io. Gagné C, Moorjani S, Brun D, et al. Heterozygous familial hypercholesterolemia: relationship between plasma lipids, lipoproteins, clinical manifestations and ischaemic heart disease in men and women. Atherosclerosis 1979;34:13-24.

II. Neil HAW, Hammond T, Huxley R, et al. Extent of underdiagnosis of familial hypercholesterolaemia in routine practice: prospective registry study. BMJ 2000;321:I48.

I2. Müller C. Xanthomata, hypercholesterolemia, angina pectoris. Acta Med Scand I939;89:75-84.

I3. Austin MA, Hutter CM, Zimmern RL, et al. Genetic causes of monogenic heterozygous familial hypercholesterolemia: a HuGE prevalence review. Am J Epidemiol 2004;160:407-20.

I4. Rader DJ, Cohen J, Hobbs HH. Monogenic hypercholesterolemia: new insights into pathogenesis and treatment. J Clin Invest 2003;1II:1795-803.

I5. Jeon H, Blacklow SC. Structure and physiologic function of the low-density lipoprotein receptor. Annu Rev Biochem 2005;74:535-62.

16. Heath KE, Gahan M, Whittall RA, et al. Low-density lipoprotein receptor gene $(L D L R)$ world-wide website in familial hypercholesterolaemia: update, new features and mutation analysis. Atherosclerosis 200I; 154:243-6.

17. Scientific Steering Committee; Simon Broome Register Group. Risk of fatal coronary heart disease in familial hypercholesterolaemia. BMJ I991;303:893-6.

I8. Williams RR, Hunt SC, Schumacher MC, et al. Diagnosing heterozygous familial hypercholesterolemia using new practical criteria validated by molecular genetics. Am J Cardiol 1993; 72:171-6.

I9. Fouchier S, Defesche J, Umans-Eckenhausen M, et al. The molecular basis of familial hypercholesterolemia in the Netherlands. Hum Genet 2001;109:602-I5.

20. Hadfield SG, Humphries SE. Implementation of cascade testing for the detection of familial hypercholesterolaemia. Curr Opin Lipidol 2005;16:428-33.

2I. Damgaard D, Larsen ML, Nissen PH, et al. The relationship of molecular genetic to clinical diagnosis of familial hypercholesterolemia in a Danish population. Atherosclerosis 2005; $180: 155-60$.
22. Civeira F; International Panel on Management of Familial Hypercholesterolemia. Guidelines for the diagnosis and management of heterozygous familial hypercholesterolemia. Atherosclerosis 2004;173:55-68.

23. Leren TP, Manshaus T, Skovholt U, et al. Application of molecular genetics for diagnosing familial hypercholesterolemia in Norway: results from a family-based screening program. Semin Vasc Med 2004;4:75-85.

24. Moorjani S, Roy M, Gagne C, et al. Homozygous familial hypercholesterolemia among French Canadians in Quebec Province. Arteriosclerosis I989;9:21I-6.

25. Ma YH, Bétard C, Roy M, et al. Identification of a second "French Canadian" LDL receptor gene deletion and development of a rapid method to detect both deletions. Clin Genet 1989;36:219-28.

26. Leitersdorf E, Tobin EJ, Davignon J, et al. Common low-density lipoprotein receptor mutations in the French Canadian population. J Clin Invest I990;85:10I4-23.

27. Couture P, Morissette J, Gaudet D, et al. Fine mapping of low-density lipoprotein receptor gene by genetic linkage on chromosome 19p13.1-p13.3 and study of the founder effect of four French Canadian low-density lipoprotein receptor gene mutations. Atherosclerosis 1999;I43:I45-5I.

28. Simard J, Moorjani S, Vohl MC, et al. Detection of a novel mutation (stop 468) in exon to of the low-density lipoprotein receptor gene causing familial hypercholesterolemia among French Canadians. Hum Mol Genet I994;3:I689-9I.

29. Assouline L, Leitersdorf E, Lambert M, et al. Identification of two novel LDL receptor gene defects in French-Canadian pediatric population: mutational analysis and biochemical studies. Hum Mutat 1997;9:555-62.

30. Couture P, Vohl MC, Gagné C, et al. Identification of three mutations in the lowdensity lipoprotein receptor gene causing familial hypercholesterolemia among French Canadians. Hum Mutat I998; Suppl 1:S226-31.

3I. Andersen LK, Jensen HK, Juul S, et al. Patients' attitudes toward detection of heterozygous familial hypercholesterolemia. Arch Intern Med 1997;157:553-60.

32. Umans-Eckenhausen MA, Defesche JC, Sijbrands EJ, et al. Review of first 5 years of screening for familial hypercholesterolaemia in the Netherlands. Lancet 200I; 357:165-8.

33. Genest J, Frohlich J, Fodor G, et al. Recommendations for the management of dyslipidemia and the prevention of cardiovascular disease: summary of the 2003 update [published erratum in CMAJ 2003;I69(II):II49]. CMAJ 2003;I69(9):92I-4.

34. Marks D, Thorogood M, Neil HA, et al. A review on the diagnosis, natural history, and treatment of familial hypercholesterolaemia. Atherosclerosis 2003;I68:I-I4.

35. Ketomaki A, Gylling H, Miettinen TA. Effects of plant stanol and sterol esters on serum phytosterols in a family with familial hypercholesterolemia including a homozygous subject. J Lab Clin Med 2004;143:255-62.

36. Miettinen TA, Gylling H. Plant stanol and sterol esters in prevention of cardiovascular diseases. Ann Med 2004;36:126-34.

37. Hopkins PN. Familial hypercholesterolemia: improving treatment and meeting guidelines. Int J Cardiol 2003;89:13-23

38. Stein EA, Illingworth DR, Kwiterovich PO Jr, et al. Efficacy and safety of lovastatin in adolescent males with heterozygous familial hypercholesterolemia: a randomized controlled trial. JAMA 1999;281:137-44.

39. de Jongh S, Ose L, Szamosi T, et al.; Simvastatin in Children Study Group. Efficacy and safety of statin therapy in children with familial hypercholesterolemia: a randomized, double-blind, placebo-controlled trial with simvastatin. Circulation 2002;106:2231-7.

40. McCrindle BW, Ose L, Marais AD. Efficacy and safety of atorvastatin in children and adolescents with familial hypercholesterolemia or severe hyperlipidemia: a multicenter, randomized, placebo-controlled trial. J Pediatr 2003;I43:74-80.

4I. van Wissen S, Smilde TJ, Trip MD, et al. Long-term safety and efficacy of high-dose atorvastatin treatment in patients with familial hypercholesterolemia. Am J Cardiol 2005;95:264-6.

42. Wiegman A, Hutten BA, de Groot E, et al. Efficacy and safety of statin therapy in children with familial hypercholesterolemia: a randomized controlled trial. JAMA 2004;292:33I-7.

43. Goldman L, Goldman PA, Williams LW, et al. Cost-effectiveness considerations in the treatment of heterozygous familial hypercholesterolemia with medications. Am J Cardiol I993;72:75D-9D.

44. Wonderling D, Umans-Eckenhausen MA, Marks D, et al. Cost-effectiveness analysis of the genetic screening program for familial hypercholesterolemia in the Netherlands. Semin Vasc Med 2004;4:97-104.

45. Pearson TA, Denke MA, McBride PE, et al. A community-based, randomized trial of ezetimibe added to statin therapy to attain NCEP ATP III goals for LDL cholesterol in hypercholesterolemic patients: the Ezetimibe Add-on to Statin for Effectiveness (EASE) trial. Mayo Clin Proc 2005;80:587-95.

46. McKenney JM. Pharmacologic options for aggressive low-density lipoprotein cholesterol lowering: benefits versus risks. Am J Cardiol 2005;96:60E-66E.

47. Guyton JR, Goldberg AC, Kreisberg RA, et al. Effectiveness of once-nightly dosing of extended-release niacin alone and in combination for hypercholesterolemia. Am J Cardiol I998;82:737-43.

48. Marks D, Thorogood M, Neil HA, et al. Comparing costs and benefits over a Io year period of strategies for familial hypercholesterolaemia screening. J Public Health Med 2003;25:47-52.

Correspondence to: Dr. Robert A. Hegele, Blackburn Cardiovascular Genetics Laboratory, Robarts Research Institute, 406-Ioo Perth Dr., London ON N6A 5K8; fax 519 663-3037; hegele@robarts.ca 